\title{
Safety and efficacy of rosiglitazone in the elderly diabetic patient
}

This article was published in the following Dove Press journal:

Vascular Health and Risk Management

28 April 2009

Number of times this article has been viewed

\author{
Adie Viljoen' \\ Alan Sinclair ${ }^{2}$ \\ 'Department of Chemical Pathology, \\ Lister Hospital, Stevenage, \\ Hertfordshire, UK; ${ }^{2}$ Bedfordshire \\ and Hertfordshire Postgraduate \\ Medical School, Putteridge Bury \\ campus, Luton, Bedfordshire, UK
}

\begin{abstract}
Diabetes is an important health condition for the aging population; at least $20 \%$ of patients over the age of 65 years have diabetes, and this number can be expected to grow rapidly in the coming decades. Rosiglitazone, a drug in the thiazolidinedione class which targets insulin resistance, was approved by drug regulatory bodies based on its ability to improve glycemic control nearly ten years ago. The greatest long-term risk in diabetes is cardiovascular disease with macrovascular disease being the cause of as much as $80 \%$ of mortality. More recently the cardiovascular safety of rosiglitazone was brought to center stage following several metaanalyses and the unplanned interim analysis of the RECORD trial. As opposed to pioglitazone, current evidence points to rosiglitazone having a greater risk of myocardial ischemic events than placebo, metformin, or sulfonylureas. A thiazolidinedione class effect however seems apparent with respect to the increased risk for fractures and congestive heart failure. Clinical trial evidence on rosiglitazone therapy in the elderly is limited. The available evidence is mainly related to observational cohort studies. Most of the trial evidence relates to a younger population and therefore these data can not be directly extrapolated to an older population. The effects of the thiazolidinedione drug class remain incompletely understood.
\end{abstract}

Keywords: rosiglitazone, elderly, cardiovascular disease, thiazolidinedione, type 2 diabetes

\section{Introduction}

Significant advances in diabetes care have been made over the past two decades with a mounting body of evidence underscoring the benefits of glycemic control, ${ }^{1}$ lipid and blood pressure management ${ }^{1-4}$ and contributing to our current understanding of comprehensive diabetes care which addresses multiple risk factors. ${ }^{5}$ Despite this, the residual risk remains substantial with the risk of cardiovascular disease (CVD) in the diabetic population being two- to four-fold higher compared to the general population and as many as $80 \%$ of all people with diabetes will die from macrovascular complications. ${ }^{6}$ Diabetes is an important health condition for the aging population; at least $20 \%$ of patients over the age of 65 years have diabetes, and this number can be expected to grow rapidly in the coming decades. ${ }^{7}$ Despite numerous blood glucose-lowering medications being currently available and with several more drug classes having been recently developed, there is a dearth of high-quality studies that provide head-to-head comparisons of the ability of these medications to achieve the currently recommended glycemic levels. ${ }^{8}$

One such class of drugs, namely thiazolidinediones (TZDs), has been marketed for the last decade. Rosiglitazone (Avandia; GlaxoSmithKline, Brentford, UK) is a TZD, a class of drugs which targets insulin resistance. The TZDs are selective ligands of the nuclear transcription factor peroxisome-proliferator-activated receptor- $\gamma(\operatorname{PPAR} \gamma) .{ }^{9}$ The PPARs 
are a subfamily of the nuclear-receptor superfamily which regulates gene expression in response to ligand binding. ${ }^{10}$ The TZDs sensitize end organs to insulin through their action on PPAR $\gamma$ which make them potentially useful agents to lower blood glucose concentrations.

This discovery was followed by several clinical trials which proved the efficacy of this new class of antiglycemic agents. ${ }^{11-16}$ The first TZD, troglitazone, was approved in 1997 but it was subsequently withdrawn from the market in March 2000 because of hepatotoxicity. In 1999, the two currently available PPAR agonists, rosiglitazone and pioglitazone were approved in the United States. These had less hepatotoxicity but were associated with hemodilution, anemia, weight gain, edema, and increased risk for heart failure. More recently, after nearly a decade of use, the Food and Drug Administration (FDA) concluded in July 2007 that the use of rosiglitazone for the treatment of T2DM was associated with a greater risk of myocardial ischemic events than placebo, metformin, or sulfonylureas. ${ }^{17}$

\section{PPARs}

Since the discovery of PPARs by Isselman and Green in 1990, these molecules have been shown to play a major role in a diverse group of processes and pathological conditions associated with aging, inflammation, immunity, obesity, cancer, and fertility. ${ }^{18,19}$ PPARs regulate gene transcription by two mechanisms namely transactivation and transrepression. ${ }^{9}$ In transactivation, which is DNA-dependent, PPAR $\gamma$ forms a heterodimer with the retinoid $X$ receptor (RXR) and recognizes specific DNA response elements called PPAR response elements (PPRE) in the promoter region of target genes. This results in transcription of PPAR $\gamma$ target genes. In transrepression, PPARs can repress gene transcription by negatively interfering with other signal-transduction pathways, such as the nuclear factor- $\kappa \mathrm{B}(\mathrm{NF} \kappa \mathrm{B})$ signaling pathway, in a DNA-binding-independent manner.

Three PPAR isotypes, namely, PPAR $\alpha$, PPAR $\beta$ (or $\delta$ ), and PPAR $\gamma$ have been identified. They display differential tissue distribution with PPAR $\alpha$ being expressed mainly in the liver, skeletal, and cardiac muscle and in the endothelial cells and smooth-muscle cells of the vascular wall. It regulates genes that influence lipoprotein metabolism and fatty acid uptake and oxidation as well as production of inflammatory markers. Fibrates such as fenofibrate, bezafibrate, ciprofibrate, and gemfibrozil act as full or partial PPAR $\alpha$ agonists. ${ }^{20}$ PPAR $\beta$ is expressed in many tissues, with the highest expression in the skin, brain, and adipose tissue. PPAR $\gamma$ is expressed most abundantly in adipose tissue but is also found in pancreatic beta cells, vascular endothelium, and macrophages. ${ }^{21}$ PPAR $\gamma$ was originally identified as a central regulator of gene expression and differentiation in adipose cells. ${ }^{22}$

\section{Thiazolidinediones: Mechanism of action}

Both nondiabetic subjects and those with type 2 diabetes mellitus (T2DM) show increased insulin-stimulated glucose uptake in peripheral tissues as well as increased hepatic insulin sensitivity (the ability of insulin to suppress endogenous glucose production) and insulin sensitivity in adipose tissue (measured from the ability of insulin to suppress free fatty acid concentrations). ${ }^{9,23,24}$ The mechanisms by which insulin sensitization occurs are thought to involve either direct action on fatty acid uptake and storage in adipose tissue (also known as the fatty steal hypotheses) or indirectly via its action adipokines such adiponectin. ${ }^{25}$ The free fatty acid storage in adipose tissue as opposed to liver and skeletal most likely exerts a protective effect on these tissues. In addition, advantageous effects on the beta cells of the pancreas may occur by inhibiting glucolipotoxicity. ${ }^{26}$ Taken together, the mechanisms of action are complex and multifold and the many effects of TZDs in various tissues make it impossible to define all the exact mechanisms underlying their insulinsensitizing effects in vivo in humans. ${ }^{9}$

\section{Rosiglitazone and cardiovascular disease: A timeline of events}

Cardiovascular disease is a very common complication of diabetes in up to $80 \%$ of all people with diabetes who die from macrovascular complications. It would therefore be prudent to evaluate the effects of any hypoglycemic agent on cardiovascular outcomes. Furthermore, improving glycemic control does not equate to improved CVD outcomes and in fact may lead to the contrary. ${ }^{27}$ Following marketing in 1999 in the United States and 2000 in Europe, it became clear that both rosiglitazone and pioglitazone increased the risk of congestive heart failure (CHF). A World Health Organization (WHO) report in 2003 suggested that TZDs might increase risk for cardiac disease which prompted GlaxoSmithKline (GSK) to submit preliminary pooled analyses of its cardiovascular safety to the FDA in $2005 .^{28}$ The FDA's review of these and other data led to the first rosiglitazone label warnings about possible cardiac adverse effects other than heart failure, particularly in patients also receiving insulin. ${ }^{28}$ In August 2006, the FDA received GSK's formal analysis of 42 randomized trials along with data from a large observational study. The meta-analysis suggested a possible " $31 \%$ increase in cardiac ischemic events with 
rosiglitazone," whereas the observational study showed no such increased risk. ${ }^{28,29}$ In September 2006, the DREAM (Diabetes REduction Assessment with ramipril and rosiglitazone Medication) Trial which was a placebo-controlled trial in pre-diabetic patients, the largest randomized study of rosiglitazone, showed a not statistically significant increase in risk for myocardial infarction $(1.2 \%$ vs $0.9 \% ; \mathrm{p}=0.2)$ among over 5000 patients treated with rosiglitazone. ${ }^{30}$ In December 2006, the ADOPT (A Diabetes Outcome Progression Trial) study, a trial involving diabetic patients showed similar numbers of heart failure and ischemic events with rosiglitazone and metformin that were higher than those found with glyburide. ${ }^{31}$ In May 2007, the cardiovascular safety of rosiglitazone was brought to center stage following the meta-analyses published by Nissen and Wolski $^{32}$ which claimed that rosiglitazone increased the risk for myocardial infarction by about $43 \%$ and cardiovascular death by about $64 \%$. The limitations of this study lead to significant discussion. This triggered an unplanned interim analysis of the RECORD (Rosiglitazone Evaluated for Cardiac Outcomes and Regulation of Glycaemia in Diabetes) trial, ${ }^{33}$ a prospective outcomes study evaluating add-on rosiglitazone to metformin or sulfonylurea which showed 217 patients in the rosiglitazone group and 202 patients in the control group to have the adjudicated primary end point (hazard ratio [HR], 1.08; 95\% confidence interval [CI]: 0.89-1.31). No statistical difference between the two groups could therefore be shown and the final analysis should help answer the question on cardiovascular safety. Another meta-analysis of rosiglitazone therapy that included long-term trials only (duration $>12$ months) where the majority of cardiovascular events were adjudicated showed rosiglitazone use to be associated with a similar increase in myocardial infarction incidence across all trials (relative risk [RR], 1.42; 95\% CI: 1.06-1.91; $\mathrm{p}=0.02) .{ }^{34}$ A meta-analyses performed by both the manufacture ${ }^{35}$ and a Cochrane review ${ }^{36}$ had similar conclusions. Finally a meta-analysis by the US FDA $^{28}$ lead to the FDA's conclusion at the end of July 2007 that the use of rosiglitazone for the treatment of T2DM was associated with a greater risk of myocardial ischemic events than placebo, metformin, or sulfonylureas. ${ }^{17}$ In part, these events have lead to a re-evaluation of the relative importance of surrogate markers as opposed to hard end point data which is imperative to guide clinical decision making. ${ }^{17,37,38}$

\section{Diabetes and the elderly}

Diabetes is an important health condition for the aging population. At least $20 \%$ of patients over the age of 65 years have diabetes, and this number can be expected to grow rapidly in the coming decades. Older individuals with diabetes have higher rates of premature death, functional disability, and coexisting illnesses such as hypertension, CHD, and stroke than those without diabetes. Older adults with diabetes are also at greater risk than other older adults for several common geriatric syndromes, such as polypharmacy, depression, cognitive impairment, urinary incontinence, injurious falls, and persistent pain. ${ }^{7}$ The care of older adults with diabetes is complicated by their clinical and functional heterogeneity. In the past, clinical trials of diabetes therapies such as the United Kingdom Prospective Diabetes Study (UKPDS) systematically excluded patients above the age of 65 years. While age restrictions are slowly being raised, clinical trial evidence remains sparser in the elderly population. Unless the patient population in the clinical trial is representative of the intended treatment population results and treatment decisions can not simply be extrapolated. The problem with extrapolating results from clinical trials into clinical practice is twofold. The clinical trial populations have to reflect the heterogeneity of the general population of elderly diabetes patients. This requires that clinicians extrapolate findings from healthier, compliant trial patients to the care of elderly patients. Secondly, trial evidence in a younger population can not simply be extrapolated to an older population.

\section{Trial evidence in the elderly}

Unfortunately the evidence from clinical trials specifically focusing on rosiglitazone use in elderly population is sparse and relatively limited. For the ADOPT trial, patients between the ages of 30 and 75 years were eligible. However, the population was not entirely representative of the elderly population with the respective means and standard deviations (SD) for the three arms being $56.3 \pm 10$ (rosiglitazone), $57.9 \pm 9$ (metformin) and $56.4 \pm 10.2$ years (glyburide). ${ }^{31}$ In the RECORD study the respective means and SDs for both the rosiglitazone and control arms were $58 \pm 8.3$ years. ${ }^{33}$ The weighted adjusted mean ages of the 2007 meta-analysis by Nissen and Wolski ${ }^{30}$ were 56.1 (rosiglitazone) and 56.9 years (control) group. The mean ages for patients in the DREAM trial were 54.6 (rosiglitazone) and 54.8 (placebo) arms. ${ }^{30}$ All these studies are therefore not entirely representative of the elderly population.

Two recent studies specifically investigated and compared the effects of rosiglitazone and pioglitazone in the elderly population. The first was a large populationbased, retrospective cohort study of 159,026 patients of $\geq 66$ years (mean age 75 years). The analysis employed a nested case-control approach and concluded that rosiglitazone and not pioglitazone had an increased risk of 
congestive heart failure, acute myocardial infarction, and mortality when compared with other combination oral hypoglycemic agent treatments. ${ }^{39}$ The second study included another large cohort of 28,361 patients older than 65 years who had initiated treatment with either rosiglitazone or pioglitazone. ${ }^{40}$ The study outcomes included all-cause mortality, myocardial infarction, stroke, and hospitalization for CHF. After adjustment for a large number of patient characteristics, a 15\% greater mortality among patients who initiated therapy with rosiglitazone compared with pioglitazone (95\% CI: 5\%-26\%) was demonstrated. Use of rosiglitazone was also associated with a $13 \%$ greater risk of congestive heart failure (95\% CI: 1\%-26\%). No differences between the two drugs were found in their rates of myocardial infarction or stroke. This is the first study known specifically aimed at detecting any differences in relative cardiovascular safety between these two TZDs in elderly patients. The limitations of these cohort studies are primarily due to nonrandomization, less strict adjudication of outcomes, and control of adherence to therapy. Unfortunately only sparse information has become available from head-to-head comparisons between these two drugs and one is therefore restricted to this lower level of evidence. One of the few head-to-head studies between rosiglitazone and pioglitazone randomized 802 patients with T2DM treated by diet alone or monotherapy with an oral hypoglycemic agent. The effects these two TZDs had on lipid levels and glycemic control were evaluated over a 24 -week period. ${ }^{44}$ Although the drugs achieved similar glycemic control, the study revealed lipid effects that markedly favored pioglitazone over rosiglitazone. However, the study was clearly not designed or powered to detect differences in important long-term clinical outcomes. More so, these data can not be simply extrapolated to the elderly population as mean \pm SD was $55.9 \pm 10.5$ for the pioglitazone arm and $56.3 \pm 11.3$ years for the rosiglitazone arm.

\section{Rosiglitazone versus pioglitazone and cardiovascular disease}

These two TZDs seem to have disparate effects with respect to cardiovascular outcomes. As mentioned, the interim analysis of the RECORD trial was reported in 2007 and the final analysis is awaited. For pioglitazone, the PROACTIVE (PROspective pioglitAzone Clinical Trial In macroVascular Events) study, is the only outcomes based study in TZDs to be reported thus far. ${ }^{41}$ This trial included more than 5000 patients with diabetes at high risk for macrovascular complications. Results of the trial suggested that treatment with pioglitazone was beneficial from the cardiovascular standpoint. However, significant differences were not observed in the pre-specified primary end point (death, myocardial infarction, stroke, acute coronary syndrome, leg amputation, or coronary or leg revascularization). However, for a secondary end point of death, myocardial infarction, or stroke, a statistically significant benefit was observed. A meta-analysis of pioglitazone investigating pioglitazone treatment which included 19 trials involving more than 16,000 patients reported a significant reduction in death, myocardial infarction, or stroke occurring in 375 of 8554 patients (4.4\%) receiving pioglitazone and 450 of 7836 patients $(5.7 \%)$ receiving control therapy (HR, 0.82 ; 95\% CI: $0.72-0.94 ; \mathrm{p}=0.005) .{ }^{42}$ It has been argued that these findings may have been driven primarily by the PROactive trial which lead to a second meta-analysis of 94 trials that excluded the PROactive trial. This study concluded that pioglitazone was associated with reduced all-cause mortality with no relevant effect on nonfatal coronary events. ${ }^{43}$ The reason why these seemingly disparate results between these two TZDs may exist, is unclear. It may in part be explained by the difference these two drugs have on both lipoprotein and apolipoprotein concentrations. ${ }^{44-46}$ The previously mentioned randomized trial of 802 patients with T2DM treated by diet alone or monotherapy with an oral hypoglycemic agent compared the effects of these two TZDs on lipid levels and glycemic control for 24 weeks. ${ }^{44}$ Pioglitazone was associated with a reduction in triglycerides whereas rosiglitazone increased concentrations. Both medications raised low-density lipoprotein-cholesterol (LDL-C); however, the increase was significantly greater with rosiglitazone compared to pioglitazone. Pioglitazone did not significantly change apolipoprotein B levels but did reduce LDL particle concentration. Conversely, rosiglitazone increased both apolipoprotein B and LDL particle concentration. Both medications increased high-density lipoprotein cholesterol (HDL-C) with pioglitazone having no effect on serum apolipoprotein AI levels, but rosiglitazone was associated with a decrease in apolipoprotein AI levels. ${ }^{44,45}$ All these changes deem rosiglitazone to have a less favorable effect on the lipid profile compared to pioglitazone. Furthermore, different PPAR agonists can yield markedly different patterns of gene modulation which will result in complex and largely unknown differences in effects on metabolic pathways. ${ }^{47}$

\section{TZDs and heart failure}

The TZDs have been contraindicated in patients with all stages of heart failure (New York Heart Association class I-IV) since their approval in Europe by the European 
Medicines Agency (EMEA) ${ }^{48}$ in contrast to the Unites States, where their use is not contra-indicated among diabetic patients in early stages of heart failure (New York Heart Association class I-II). ${ }^{49}$ A teleo-analysis of three randomized trials, four controlled observational studies, 28 anecdotal case reports/case series, and 214 spontaneous reports in a Canadian database reported that both rosiglitazone and pioglitazone were associated with an approximate doubling of the risk of CHF in patients with type 2 diabetes (OR, 2.1; 95\% CI: $1.08-4.08 ; \mathrm{p}=0.03) .{ }^{50}$ This analysis estimated the number needed to harm with TZDs, based on an OR of 2.10 to would be approximately 50 over a 2.2-year follow-up period. This study reported on the ages of the four observational studies in 67,382 patients and concluded that the adverse effect was not limited to the elderly because 42 of 162 case subjects $(26 \%)$ were aged less than 60 years. Separate metaanalyses of both rosiglitazone and pioglitazone confirmed this increased risk with both rosiglitazone and pioglitazone, pointing to a class effect. ${ }^{32,42,50,51}$

\section{Rosiglitazone and risk of fractures}

As recently as 2006 the skeletal effects of TZDs in humans were limited to observational studies. The first clinical study to report on an increased bone loss with TZD use was the Health, Aging, and Body Composition longitudinal observational study of older adults. ${ }^{52}$ The cohort included 666 diabetic participants with an average age of 73 years. Of these, 69 participants reported any TZD use during four years of follow-up. Increased bone loss was found in diabetic women but not men.

More definitive evidence came after the ADOPT trial where it was demonstrated that rosiglitazone increased the risk of fractures. ${ }^{31}$ The trial enrolled 2511 men and 1840 women and assessed monotherapy failure in recently diagnosed drug-naïve type 2 diabetics. The investigators found an increased risk of fractures among women in the rosiglitazone arm of 1.81 (95\% CI: 1.17, 2.80) compared to metformin and 2.13 (95\% CI: 1.30, 3.51) compared to glyburide. The risk for men was not increased. The risk in women was increased for both upper and lower limb fractures. The ADOPT trial contained data on self-reported menopausal status and baseline use of estrogen-containing hormones. As expected, premenopausal women had a lower rate of fracture than postmenopausal women. Both pre- and postmenopausal groups had an approximate doubling of fracture risk with rosiglitazone treatment.

Following this report, the clinical trial database of pioglitazone was reviewed by Takeda Pharmaceuticals, the manufacturer of pioglitazone..$^{53}$ The trials databases included 8100 patients treated with pioglitazone and over 7400 patients in the comparison group. The risk for fractures showed a similar doubling as reported in the ADOPT study with rosiglitazone (1.9 per 100 person years in those using pioglitazone compared with a rate of 1.1 per 100 person years in those using placebo or an active comparator drug). The increased risk for fractures therefore also appears to be a class effect. A recent metaanalysis which included 10 randomized controlled trials that lasted at least 12 months and involved over 13,000 patients, found that thiazolidinediones were associated with a $45 \%$ increase in fractures. ${ }^{54}$

The mechanism by which this occurs is unclear. Limited studies measuring bone markers point to reduced bone formation with no changes in bone resorption. ${ }^{55,56}$ The lack of bone formation may occur via PPAR $\gamma$ stimulation which affects the regulation of the pluripotent mesenchymal stem cells stimulating differentiation into adipocytes in preference over osteoblasts. ${ }^{57}$

\section{Conclusion}

Clinical trial evidence on rosiglitazone therapy in the elderly is limited. The available evidence is mainly related to observational cohort studies. Outcome evidence for rosiglitazone even in the general population is still awaited. As opposed to pioglitazone, the current evidence of the cardiovascular risk of rosiglitazone is neutral at best with several lower graded forms of evidence pointing to cardiovascular harm. Even though the data are less than conclusive for a CVD risk with rosiglitazone or a CVD benefit with pioglitazone, the most recent joint consensus statement from the American Diabetes Association and the European Association for the Study of Diabetes unanimously advised against using rosiglitazone. ${ }^{8}$ In addition, rosiglitazone is also associated with increased risk of fractures and CHF. The effects of the thiazolidinedione drug class remain incompletely understood. Contrary to the great promise it held when it came to the market some authors now question whether the benefits outweigh the risks. ${ }^{58}$

Similar to all other drugs used to treat diabetes, rosiglitazone was approved by drug regulatory bodies based on its ability to improve glycemic control, rather than based on long-term clinical benefit. Following the occurrences with rosiglitazone and other drugs, regulatory authorities have now grown more stringent and rely less on surrogate markers while demanding more data and more quality data. The balance between causing harm and potentially denying a patient useful treatment is delicate and the evaluation remains 
complex. In the meantime clinicians are forced to make treatment decisions in the 'light' of inconclusive evidence.

\section{Disclosure}

The authors have received lecturing honoraria, traveling support, educational grant support and/or are involved in clinical research trials of Sanofi-Aventis, Merck Sharp Dohme, Schering Plough, Eli Lily, GlaxoSmithKline, Takeda, and Novartis.

\section{References}

1. UK Prospective Diabetes Study Group. Intensive blood-glucose control with sulphonylureas or insulin compared with conventional treatment and risk of complications in patients with type 2 diabetes (UKPDS 33). Lancet. 1998;352(9131):837-853.

2. Colhoun HM, Betteridge DJ, Durrington PN, et al. Primary prevention of cardiovascular disease with atorvastatin in type 2 diabetes in the Collaborative Atorvastatin Diabetes Study (CARDS): multicentre randomised placebo-controlled trial. Lancet. 2004;364(9435):685-696.

3. Collins R, Armitage J, Parish S, Sleigh P, Peto R. MRC/BHF Heart Protection Study of cholesterol-lowering with simvastatin in 5963 people with diabetes: a randomised placebo-controlled trial. Lancet. 2003;361(9374):2005-2016.

4. Cholesterol Treatment Trialists' (CTT) Collaborators, Kearney PM, Blackwell L, et al. Efficacy of cholesterol-lowering therapy in 18,686 people with diabetes in 14 randomised trials of statins: a meta-analysis. Lancet. 2008;371(9607):117-125.

5. Gaede P, Vedel P, Larsen N, et al. Multifactorial intervention and cardiovascular disease in patients with type 2 diabetes. $N$ Engl $J$ Med. 2003;348(5):383-393.

6. Kannel WB. Lipids, diabetes, and coronary heart disease: insights from the Framingham Study. Am Heart J. 1985;110:1100-1107.

7. Sinclair AJ, Finucane P, editors. Diabetes in Old Age, 3rd Ed. Hoboken, NJ: Wiley; 1995.

8. Nathan DM, Buse JB, Davidson MB, et al; American Diabetes Association; European Association for Study of Diabetes. Medical management of hyperglycemia in type 2 diabetes: a consensus algorithm for the initiation and adjustment of therapy: a consensus statement of the American Diabetes Association and the European Association for the Study of Diabetes. Diabetes Care. 2009;32(1):193-203.

9. Yki-Järvinen H. Thiazolidinediones. N Engl J Med. 2004;351(11): 1106-1118.

10. Chawla A, Repa JJ, Evans RM, et al. Nuclear receptors and lipid physiology: opening the X-files. Science. 2001;294(5548):1866-1870.

11. Aronoff S, Rosenblatt S, Braithwaite S, Egan JW, Mathisen AL, Schneider RL. Pioglitazone hydrochloride monotherapy improves glycemic control in the treatment of patients with type 2 diabetes: a 6-month randomized placebo-controlled dose-response study. Diabetes Care. 2000;23:1605-1611.

12. Kipnes MS, Krosnick A, Rendell MS, Egan JW, Mathisen AL, Schneider RL. Pioglitazone hydrochloride in combination with sulfonylurea therapy improves glycaemic control in patients with type 2 diabetes mellitus: a randomized, placebo-controlled study. Am J Med. 2001;111:10-17.

13. Raskin P, Rendell M, Riddle MC, Dole JF, Freed MI, Rosenstock J. A randomized trial of rosiglitazone therapy in patients with inadequately controlled insulin-treated type2 diabetes. Diabetes Care. 2001;24:12261232.

14. Fonseca V, Rosenstock J, Patwardhan R, Salzman A. Effect of metformin and rosiglitazone combination therapy in patients with type 2 diabetes mellitus: a randomized controlled trial. JAMA. 2000;283: $1695-1702$.
15. Iwamoto Y, Kosaka K, Kuzuya T, Akanuma Y, Shigeta Y, Kaneko T. Effects of troglitazone: a new hypoglycemic agent in patients with NIDDM poorly controlled by diet therapy. Diabetes Care. 1996;19(2):151-156.

16. Kumar S, Boulton AJ, Beck-Nielsen H, et al. Troglitazone, an insulin action enhancer, improves metabolic control in NIDDM patients. Troglitazone Study Group. Diabetologia. 1996;39(6):701-709. Erratum in: Diabetologia. 1996;39(10):1245.

17. Rosen CJ. The rosiglitazone story-lessons from an FDA Advisory Committee meeting. N Engl J Med. 2007;357(9):844-846.

18. Issemann I, Green S. Activation of a member of the steroid hormone receptor superfamily by peroxisome proliferators. Nature. 1990;347(6294):645-650.

19. Badr M. A forum for a highly important and ever-expanding field of study. PPAR Res. 2006;2006:61385.

20. van Raalte DH, Li M, Pritchard PH, Wasan KM. Peroxisome proliferator-activated receptor (PPAR)-alpha: a pharmacological target with a promising future. Pharm Res. 2004 Sep;21(9):1531-1538.

21. Walczak R, Tontonoz P. PPARadigms and PPARadoxes: expanding roles for PPARgamma in the control of lipid metabolism. J Lipid Res. 2002;43(2):177-186.

22. Rosen ED, Walkey CJ, Puigserver P, Spiegelman BM. Transcriptional regulation of adipogenesis. Genes Dev. 2000;14(11):1293-1307.

23. Nolan JJ, Ludvik B, Beerdsen P, Joyce M, Olefsky J. Improvement in glucose tolerance and insulin resistance in obese subjects treated with troglitazone. N Engl J Med. 1994;331:1188-1193.

24. Miyazaki Y, Glass L, Triplitt C, et al. Effect of rosiglitazone on glucose and nonesterified fatty acid metabolism in Type 2 diabetic patients. Diabetologia. 2001;44:2210-2219.

25. Kadowaki T, Yamauchi T, Kubota N, Hara K, Ueki K, Tobe K. Adiponectin and adiponectin receptors in insulin resistance, diabetes, and the metabolic syndrome. J Clin Invest. 2006;116(7): 1784-1792.

26. Han SJ, Kang ES, Hur KY, et al. Rosiglitazone inhibits early stage of glucolipotoxicity-induced beta-cell apoptosis. Horm Res. 2008;70: 165-173.

27. The Action to Control Cardiovascular Risk in Diabetes Study Group. Effects of intensive glucose lowering in type 2 diabetes. $N$ Engl J Med. 2008;358:2545-2559.

28. FDA Briefing Document: Joint meeting of the Endocrinologic and Metabolic Drugs Advisory Committee and the Drug Safety and Risk Management Advisory Committee. 30 July 2007. Philadelphia, PA: GlaxoSmithKline; 2007. Accessed Jan 11, 2009. Available from: http://www.fda.gov/ohrms/dockets/ac/07/briefing/2007-4308b1-02fda-backgrounder.pdf.

29. McAfee AT, Koro C, Landon J, Ziyadeh N, Walker AM. Coronary heart disease outcomes in patients receiving antidiabetic agents. Pharmacoepidemiol Drug Saf. 2007;16:711-725.

30. Gerstein HC, Yusuf S, Bosch J, et al. Effect of rosiglitazone on the frequency of diabetes in patients with impaired glucose tolerance or impaired fasting glucose: a randomised controlled trial. Lancet. 2006;368:1096-1105.

31. Kahn SE, Haffner SM, Heise MA, et al. Glycemic durability of rosiglitazone, metformin, or glyburide monotherapy. $N$ Engl J Med. 2006;355:2427-2443.

32. Nissen SE, Wolski K. Effect of rosiglitazone on the risk of myocardial infarction and death from cardiovascular causes. $N$ Engl $J$ Med. 2007;356(24):2457-2471.

33. Home PD, Pocock SJ, Beck-Nielsen H, et al; RECORD Study Group. Rosiglitazone evaluated for cardiovascular outcomes - an interim analysis. N Engl J Med. 2007;357(1):28-38.

34. Singh S, Loke YK, Furberg CD. Long-term risk of cardiovascular events with rosiglitazone: a meta-analysis. JAMA. 2007;298:1189-1195.

35. GlaxoSmithKline Study Nos. ZM2005/00181/01 and HM2006/00497/00/ WEUSRTP866: Avandia Cardiovascular Event Modeling Project and Coronary Heart Disease Outcomes in Patients Receiving Antidiabetic Agents. Accessed Jan 11, 2007. Available from: http://ctr.gsk.co.uk/ Summary/Rosiglitazone/III_CVmodeling.pdf. 
36. Richter B, Bandeira-Echtler E, Bergerhoff K, Clar C, Ebrahim S. Rosiglitazone for type 2 diabetes mellitus. Cochrane Database Syst Rev. 2007;3:CD006063.

37. Wierzbicki AS. Surrogate markers, atherosclerosis and cardiovascular disease prevention. Int J Clin Pract. 2008;62(7):981-987.

38. Mulrow CD, Cornell J, Localio AR. Rosiglitazone: a thunderstorm from scarce and fragile data. Ann Intern Med. 2007;147(8):585-587.

39. Lipscombe LL, Gomes T, Lévesque LE, Hux JE, Juurlink DN, Alter DA. Thiazolidinediones and cardiovascular outcomes in older patients with diabetes. JAMA. 2007;298(22):2634-2643.

40. Winkelmayer WC, Setoguchi S, Levin R, Solomon DH. Comparison of cardiovascular outcomes in elderly patients with diabetes who initiated rosiglitazone vs pioglitazone therapy. Arch Intern Med. 2008;168(21):2368-2375.

41. Dormandy JA, Charbonnel B, Eckland DJ, et al. Secondary prevention of macrovascular events in patients with type 2 diabetes in the PROactive Study (PROspective pioglitAzone Clinical Trial In macroVascular Events) a randomised controlled trial. Lancet. 2005;366(9493):1279-1289.

42. Lincoff AM, Wolski K, Nicholls SJ, Nissen SE. Pioglitazone and risk of cardiovascular events in patients with type 2 diabetes mellitus: a meta-analysis of randomized trials. JAMA. 2007;298(10):1180-1188.

43. Mannucci E, Monami M, Lamanna C, Gensini GF, Marchionni N. Pioglitazone and cardiovascular risk. A comprehensive meta-analysis of randomized clinical trials Diabetes Obes Metab. 2008;10(12): $1221-1238$.

44. Goldberg RB, Kendall DM, Deeg MA, et al; GLAI Study Investigators. A comparison of lipid and glycemic effects of pioglitazone and rosiglitazone in patients with type 2 diabetes and dyslipidemia. Diabetes Care. 2005;28(7):1547-1554.

45. Deeg MA, Buse JB, Goldberg RB, et al; GLAI Study Investigators. Pioglitazone and rosiglitazone have different effects on serum lipoprotein particle concentrations and sizes in patients with type 2 diabetes and dyslipidemia. Diabetes Care. 2007;30(10):2458-2464.

46. Deeg MA, Tan MH. Pioglitazone versus rosiglitazone: Effects on lipids, lipoproteins, and apolipoproteins in head-to-head randomized clinical studies. PPAR Res. 2008;2008:520465.

47. Hsiao A, Worrall DS, Olefsky JM, Subramaniam S. Variance-modeled posterior inference of microarrray data: detecting gene-expression changes in 3T3-L1 adipocytes. Bioinformatics. 2004;20(17): 3108-3127.
48. European Agency for the Evaluation of Medicinal Products (EMEA). EPARS for authorised medicinal products for human use. London, UK: Avandia; 2007. Accessed Jan 11, 2009. Available from: http://www. emea.europa.eu/humandocs/Humans/EPAR/avandia/avandia.htm.

49. Nesto RW, Bell D, Bonow RO, et al. Thiazolidinedione use, fluid retention, and congestive heart failure: a consensus statement from the American Heart Association and American Diabetes Association. Diabetes Care. 2004:27:256-263.

50. Singh S, Loke YK, Furberg CD. Thiazolidinediones and heart failure: a teleo-analysis. Diabetes Care. 2007;30:2148-2153.

51. Singh S, Loke YK, Furberg CD. Long-term risk of cardiovascular events with rosiglitazone: a meta-analysis. JAMA. 2007;298(10):1189-1195.

52. Schwartz AV, Sellmeyer DE, Vittinghoff E, et al. Thiazolidinedione use and bone loss in older diabetic adults. J Clin Endocrinol Metab. 2006;91(9):3349-3354.

53. Takeda Pharmaceuticals. Observation of an increased incidence of fractures in female patients who received long-term treatment with ACTOS ${ }^{\circledR}$ (pioglitazone $\mathrm{HCl}$ ) tablets for type 2 diabetes mellitus. March 2007. Accessed on Jan 11, 2009. Available from: http://www. fda.gov/medwatch/safety/2007/Actosmar0807.pdf.

54. Loke YK, Singh S, Furberg C. Long-term use of thiazolidinediones and fractures in type 2 diabetes: a meta-analysis. CMAJ. 2009;180(1):32-39.

55. Grey A, Bolland M, Gamble G, et al. The peroxisome proliferatoractivated receptor-gamma agonist rosiglitazone decreases bone formation and bone mineral density in healthy postmenopausal women: a randomized, controlled trial. Clin Endocrinol Metab. 2007;92(4): $1305-1310$.

56. Glintborg D, Andersen M, Hagen C, Heickendorff L, Hermann AP. Association of pioglitazone treatment with decreased bone mineral density in obese premenopausal patients with polycystic ovary syndrome: a randomized, placebo-controlled trial. J Clin Endocrinol Metab. 2008;93(5):1696-1701

57. Ali AA, Weinstein RS, Stewart SA, Parfitt AM, Manolagas SC, Jilka RL. Rosiglitazone causes bone loss in mice by suppressing osteoblast differentiation and bone formation. Endocrinology. 2005;146:1226-1235.

58. Lipscombe LL. Thiazolidinediones: Do harms outweigh benefits? CMAJ. 2009;180:16-17.
Vascular Health and Risk Management

\section{Publish your work in this journal}

Vascular Health and Risk Management is an international, peerreviewed journal of therapeutics and risk management, focusing on concise rapid reporting of clinical studies on the processes involved in the maintenance of vascular health; the monitoring, prevention and treatment of vascular disease and its sequelae; and the involvement of

\section{Dovepress}

metabolic disorders, particularly diabetes. This journal is indexed on PubMed Central and MedLine. The manuscript management system is completely online and includes a very quick and fair peer-review system, which is all easy to use. Visit http://www.dovepress.com/ testimonials.php to read real quotes from published authors. 